\title{
INSCRITURA E TRANSCULTURALIDADE COMO POESIA E CIMARRONAJE EM NICOLÁS GUILLÉN
}

\author{
INSCRITURA Y TRANSCULTURALIDAD COMO POESÍA Y CIMARRONAJE EN \\ NICOLÁS GUILLÉN
}

\section{INSCRITURA AND TRANSCULTURALIDADE AS POETRY AND CIMARRONAJE IN NICOLÁS GUILLÉN}

\author{
Rogerio Mendes \\ Universidade Federal do Rio Grande do Norte (UFRN, Brasil) \\ rogerio.mendes.coelho@ufrn.br
}

\begin{abstract}
Resumo:
Ao apresentar como as cosmogonias e as cosmovisões africanas operam e sistematizaremse como contribuições para a crítica e historiográfica literária no continente latinoamericano a proposta deste artigo pretende contribuir para visibilizar a experiência africana no continente latino-americano. A partir de articulações de conceitos como cimarronaje (Mendes) e Inscritura (Queiroz) o que se pretende com o estudo da poética de Nicolás Guillén (1959) é apresentar como se articulam a inteligência estético-performática do son como expressão genuína afro na literatura e sociedades latino-americanas. Reflexo no propósito que releva a motivação das Epistemologias do Sul, ao aproximar os fundamentos tradicionais e sapienciais que aproximam África e América, o estudo destaca importância e centralidade do patrimônio ancestral.
\end{abstract}

Palavras chaves: América Latina, experiência africana, transculturalidade, cimarronaje, inscritura, Nicolás Guillén.

\section{Resumen:}

Al presentar cómo las cosmogonías y las cosmovisiones africanas operan y se sistematizaron como contribuciones para la crítica e historiográfica literaria en el continente latinoamericano, la propuesta de este artículo pretende contribuir para visibilizar la experiencia africana en el continente latinoamericano. A partir de articulaciones de conceptos como cimarronaje (Mendes, 2019) e inscritura (Queiroz, 2007), lo que se pretende con el estudio de la poética de Nicolás Guillén (1959) es exponer cómo se articulan la inteligencia estético-representativa del sonido como expresión genuina afro en la literatura y sociedades latinoamericanas. Esto se refleja en el propósito de realzar la motivación de las Epistemologías del Sur, al aproximar los fundamentos tradicionales y sapienciales que aproximan África y América, el estudio destaca la importancia y centralidad del patrimonio ancestral.

Palabras claves: América Latina, Experiencia africana, transculturalidad, cimarronaje, inscritura, Nicolás Guillén. 


\begin{abstract}
:
By presenting how African cosmogony and cosmovision operate and are systematized as contributions to literary and historiographical criticism in Latin America, this article tries to enhance the visibility of the African experience in the aforementioned continent. Stemming from the articulation of concepts such as cimarronaje (Mendes 2019) and Inscritura (Queiroz 2007), the intention underlying the study of Nicolás Guillén's poetry (1959) is to present how son's aesthetic-performing intelligence is articulated as a genuine Afro expression in Latin American literature and societies. Reflected on the purpose that highlights the motivations of Southern Epistemologies, by bringing the traditional and sapiential fundaments that brought Africa and America closer, the study highlights the importance and centeredness of ancestral heritage.
\end{abstract}

Key words: Latin America, African experience, transculturality, cimarronaje, inscritura, Nicolás Guillén.

Recibido: 23 de agosto de $2021 \quad$ Aceptado: 09 de noviembre de 2021

\title{
Ativos performativos do corpo-palavra africano e afrodescendente
}

Compreende-se, a partir da Tradição Africana, a figura humana mediadora e difusora na metodologia e transmissão de Educação e Saberes, o griot. Pode-se compreender os griots, em acordo com Hampate Bá (2010), como casta de intelectuais responsáveis pela transmissão e perpetuação dos conhecimentos constituídos pela tradição africana ao longo do tempo. Os griots muitas vezes são comparados a artistas que recorriam à poesia, ao canto, à encenação, à música, à dança para tornar expressiva e eficaz a transmissão de suas estórias como ação performática. Um modus que a um só tempo aglutinava memória, imaginação e testemunho com várias formas de execução articuladas pela voz e corpo que conferiam ao griotismo status artístico. Para Hampate Bá (202) existiam três categorias do griotismo: 1) os griots músicos, que compunham, cantavam e tocavam instrumentos monocórdios como guitarra, corá e tantã e, dessa forma, transmitiam e preservavam a música antiga; 2) os griots embaixadores e cortesãos, vinculados à nobreza ou família real; e 3) os griots genealogistas, historiadores e poetas. Observe-se que, no conjunto dessas habilidades, o griot detinha um papel central e versátil na disseminação da cultura africana, dando à palavra caráter concêntrico e, ao mesmo tempo, "multiperspectivístico" das culturas africanas, cuja maior contribuição pode ser 
compreendida como fundamento que dinamiza a expressividade humana para além da escrita como prática comunicativa existencial que deteve na oralidade seu ponto estrutural.

Diversos autores africanos se debruçaram sobre esta relacão com a palavra para teorizarem e desenvolverem algumas práticas, como é o caso da griotique. Surgida por volta da década de 70 do século passado na Costa do Marfim, e relativa sobretudo à expressão teatral, entre seus mentores e divulgadores se encontravam dois estudiosos da questão griot: os dramaturgos e poetas marfinenses Aboubacar Cyprien Touré e Niangoran Porquet. Na perspectiva sinalizada por este último, o termo griotique traduzia um conceito literário e artístico de teatro apresentado como representativo de especificidades do teatro negro africano. Ao espelhar-se na arte performática griot, a experiência griotique reivindicou uma síntese entre poema, drama e narrativa curta, estabelecendo, portanto, um "teatro total", resultante da integracão entre o verbo, a expressão corporal, a música, a poesia, a danca e a recitacão. (Queiroz 109).

É importante frisar que a oralidade é auxiliada pelas diversas marcas expressivas como performance, que potencializam, de acordo com Queiroz (15), o "teatro total", o conceito de "Inscritura" através do qual se reconhecem as possibilidades e vias expressivas do corpo como canal de "dizibilidades" das "poéticas" e saberes ancestrais africanos. Daí a impertinência que se confere às bases que estipularam as políticas e letramentos das Nações Latino-Americanas incongruentes a não reconhecerem a diversidade das cosmogonias e cosmovisões, incluindo-se aqui as africanas que as integraram como Unidade. Talvez, por essa razão, Luiz Antonio Simas e Luiz Rufino (2018) afirmem que o corpo em "transe africano", por suas ancestralidades e saberes guardados, apresenta-se e reverta-se como representação descolonizadora, pois o colonialismo ao longo da História apresentou-se normatizador, disciplinador e domesticador dos corpos africanos que "falavam" e aprenderam a "gingar" e "driblar" como estratégia de sobrevivência para que não fossem submetidos às relações de domínio - o corpo que gerou pecado e ameaçou as catequeses; o corpo como instrumento e submissão do trabalho escravo; o corpo servil das mulheres negras e o corpo necessariamente viril para os homens negros - uma vez que é no aprisionamento e "silenciamento" do corpo que também se aprisiona a gama de saberes e ciências “encantadas”. Simas e Rufino, ainda e, no entanto, em entrevista intitulada Por una "Epistemologia Macumbera" y una Reivindicación de los Saberes Subalternizados, 
concedida à Revista Diversa - Red de Estudios de la Diversidad Religiosa en Argentina (2019), dizem que os “Saberes Outros", no caso, em específico, africanos, não colocam em "xeque" a validade e legitimidade dos saberes ocidentais modernos. O problema residiria na maneira como a política dos saberes modernos articulara-se ante a diversidade e autonomia dos "Saberes Outros" de modo a inviabilizar a coexistência e debates, ontológicos, sobre as diversas orientações e legitimação dos saberes que se afirmam, quase sempre, de maneira política e arbitrária.

O professor e pesquisador Queiroz (2007) estabelece relação arrojada e pertinente no que diz respeito aos desdobramentos dos saberes "afro-inscriturais", das relações tangiversas, entre corpo e oralidade/escrita implicadas como expressão performática nas Américas, ao longo de seus processos de formação e reinvenções das tradições culturais, nas maneiras como foram assimiladas pela dinâmica da cultura urbana. Ressalta, para isso, o processo criativo de manifestações afro-descendentes originárias das Antilhas: a poesia $d u b$, a poesia-son e o rap, como demonstrações cabais das relações tanto inventivas quanto (res)significativas envolvendo a performance concêntrica da oralidade. $\mathrm{O} d u b$ se formata a partir do reprocessamento rítmico do reggae por meio de reinterpretações condicionadas a efeitos e mixagens de estúdio que imprimiriam movimento sonoro genuíno sujeito aos tempos e expressividades da conformidade das ênfases e mensagens da palavra, como voz e performance de acordo com as circunstâncias da declamação - o que poderia incluir gritos, ruídos, silêncios e investidas percussivas pela voz:

A realização de efeitos percussivos com a voz é também um velho costume caribenho, conhecido nas Antilhas Francesas por boula gyel e, em Cuba, por descarga. Sua origem estaria na proibição e confisco dos tambores por parte dos antigos senhores coloniais, a fim de evitar as danças e cultos religiosos dos escravos. Estes hábitos culturais, no entanto, jamais deixariam de existir, substituídos que foram por uma cada vez mais sofisticada técnica de percussão vocal. Tal habilidade serviria também, como se viu aqui, de suporte criativo durante o recital $d u b$. (Queiroz 125).

Outro exemplo destacado diz respeito à poesía-son, do jornalista e poeta afrocubano Nicolás Guillén, que fundiu a oralidade e temas da poesia popular e a música tradicional, son, cubanos. O crítico literário peruano Jose Miguel de Oviedo (Cit. en 
Queiroz 125), sobre a construção poética son, no livro referencial "Motivos de Son” e "Songoro Cosongo", do poeta Nicolás Guillén, diz que sua poesia define-se, a priori, a partir de estruturas reconhecíveis da performance oral, de origem afro-hispana, em esquemas rítmicos, e não necessariamente metrificados, divididos em partes distintas e complementares: recitativos, quando se expõe o tema central seguido de um comentário ou conclusão, "montuno", que se repetiria numa espécie de refrão de intencionalidade irônica, crítica e/ou sonora sobre a relação de pessoas comuns e situações e/ou comportamentos do cotidiano cubano mediados pelos movimentos e ímpetos corporais.

Surgido em cuba em meados do século XVII, o son é uma espécie de célula ou matriz cultural caracterizada pela combinação entre música, dança e poesia de tradição oral que se desdobrou em diversas outras manifestações da cultura nas Américas, influenciando diretamente a lírica de autores como Guillén [...] (Queiroz 126).

Por fim, ao contrário do que muitos possam pensar, o rap possui relação com a América Latina em sua formatação, pois surge associado ao movimento hip-hop, que, pela aproximação da dissidência hispânica e caribenha nos Estados Unidos, torna-se prática comum entre os jovens afros, hispano-estadunidenses e brancos marginalizados, companheiros de periferia. O grafite, inclusive, relê os códices e os muralismo mexicanos, reprocessados nas ruas; o break assimila os movimentos corpóreos de celebração africana pela relação afrodiaspórica, ressignificando a violência urbana e o trauma da Guerra do Vietnã e, por essa razão, Queiroz (126) exemplifica a substancialidade do corpo das dinâmicas das ressignificações culturais pela oralidade e apresenta o rap como relevante manifestação e legado da Inscritura e expressividade como letramento afrodescendente. O rhythm and poetry toma forma nos Estados Unidos na década de setenta a partir da experiência toaster jamaicana, recitativos rítmicos de voz que imprimiam sonoridade e significados, críticos e espirituosos, em cima de bases produzidas pelos DJ. Pode-se dizer que a prática rapper possui influência direta do modo como operavam os griots. Isso porque os rappers não se limitam à enunciação crítico-discursiva, já que também se vinculam a outras modalidades expressivas como a dança e o grafite, integrados à cultura hip-hop e, dessa forma, configuram ou atualizam a ideia de "teatro total" ou "Inscritura" proposta pelo próprio Queiroz (2007), que, ao mesmo tempo, marca o perfil da 
Artículo. Rogerio Mendes. "Inscritura e transcuturalidade como poesia e cimarronaje em Nicolás Guillén"

expressividade genuína e movente, ancestral, africana. Queiroz (2007) demonstra, com isso, que a compreensão das manifestações ancestrais africanas não se configura estanque e apresenta-se dinâmica na medida que dialoga com outras culturas sem deixar, com isso, de preservar essencialidades e funções expressivas que se naturalizam com as marcas e os marcos do Tempo. Mais: apresenta uma das vias da dimensão artístico-intelectual, possível, da cimarronaje como "ginga", pedagogia, rebeldia e crítica que aferem diretrizes que configuram a pertinência do que poderia apresentar-se e compreender-se como o genuíno perfil do intelectual afrodescendente ou a versão mais contemporânea de um cimarrón, agora, ciente, crítico e letrado, porta-voz de iluminismo mestiço e testemunha viva dos saberes ausentes da Cidade Letrada.

\section{A Origem Cubana do Son}

Observa-se que há mais hipóteses do que consensos em estudos formais no que diz respeito à origem do son cubano. Sabe-se, no entanto, que, em sua base, o son pode ser compreendido como uma manifestação (trans)cultural, popular, performática, multidisciplinar aos modos como supõe o peruano Nicomedes Santa $\mathrm{Cruz}^{1}$ quando especula

\footnotetext{
${ }^{1}$ Nicomedes Santa Cruz no artigo Los trovadores Aztecas (334), afirma o México como indício de origem do son. Do "Atlántico al Pacífico y del Rio Bravo al Istmo de Tehuantepec la música, el baile y el canto mexicanos tienen por nombre el son [...]". A palavra origina-se de um topônimo local e, como se observa, relaciona-se a uma compreensão holística de manifestação cultural espontânea performativa. $O$ entendimento torna-se ainda mais "complexo" à medida que se observa e compreende o son como gênero lírico que acompanha manifestações da linguagem corporal e música. Por essa razão, trata-se de uma manifestação lírico-musical, lírico-dançante, lírico-musical-dançante, acompanhada por cantos nos quais se alternam solistas e duetos ou trios com pequena orquestra de cordas e com a coreografia de "duplas soltas" que acompanham em sapateado, que, segundo Nicomedes Santa Cruz, é um elemento contributivo da região da Andaluzia. Elemento, provavelmente, transculturado a partir das relações coloniais espanholas no México.

Não se sabe ao certo a data em que se observam as primeiras manifestações, mas Nicomedes Santa Cruz identifica, a partir das observações de um escriba chamado Vicente Saldívar, em documento histórico que data de 1776, uma denúncia do Santo Ofício da Inquisição contra manifestações em festas denominadas Chuchumbé no Porto de Veracruz, uma das regiões mexicanas com maior presença de afrodescendentes mexicanos, o que também foi identificado em outras regiões de maior incidência de afro-mexicanos, como Costa Chica de Guerrero, La Huasteca e Istmo de Tehuantepec. Nesse documento, segundo Santa Cruz, o son foi compreendido como manifestação profana e escandalosa, praticada em lugares considerados "ordinários". No texto, o peruano descreve a dança a partir da leitura do documento:
}

[...] con ademanes, meneos, zarandeos, contrarios todos a la honestidad de los que lo ven como asistentes, por mezclarse en el manoseos de tramo en tramo, abrazos y dar barriga con barriga; bien que también me informan que esto se baila en casas ordinárias, de mulatos y gente de "color quebrado", no en gente seria, ni entre hombres circunspetos y sí entre soldados, marineros y brozas. (Santa Cruz 335). 
sobre uma das hipóteses de sua origem, no México, onde dá pistas sobre a maneira como fora transculturado em diversas localidades. No entanto, observa-se que, em Cuba, vinculase como sociabilidade e cultura afrodescendentes manifestas e transfiguradas ao modo inscritural Queiroz (2007). Ou seja: uma manifestação cultural afrodescendente cuja estrutura perfaz-se de maneira multimodal, envolvendo e dinamizando possibilidades disciplinares da linguagem e letramento afrodescendentes como performance.

Tendo-se como eje a poética de Nicolás Guillén, observa-se o son como fenômeno resultante da subversão do idioma peninsular espanhol a partir das assimilações espontâneas que os afrodescendentes cubanos impetraram de maneira corrente no cotidiano. Essa "assimilação e internalização torta" do idioma oficial castelhano tornou-se destacado instrumento de articulação poética afrodescendente e, também, metáfora crítica de insubordinação política, cimarrona, anticolonial, em Cuba. Uma linguagem que em sua natureza espontânea imprimiu ritmo e musicalidade que favoreciam danças e performances, aproximando-se de um teatro total que traduziria a natureza e letramento afrodescendente originário como expressão de uma identidade nacional pelos negros em Cuba. Principalmente se levarmos em consideração, por meio das hipóteses levantadas por Nicomendes Santa Cruz, o caráter lúdico, espontâneo, recreativo e de sociabilidade cotidiana que unia as pessoas pela música. Foi por meio do son que se mantiveram terminologias e expressões africanas no uso corrente da língua espanhola em Cuba, tal como acontecera também por meio das suas religiosidades. Ao contrário do criole, o que se desenvolveu em Cuba como linguagem envolvendo as línguas espanhola e africanas favoreceu a notabilidade de um fenômeno transcultural que permitiu a visibilidade de uma fonética afrodescendente, pois, enquanto o idioma castelhano oficial afirmava-se e

Por essa razão, é provável que o son tenha se originado a partir de confluências manifestas nos portos mexicanos como uma forma de entretenimento dos diversos povos, "marginais", que ali se encontravam. Nicomedes Santa Cruz faz menções, a partir de evidências de estudos de pesquisadores do Instituto Nacional de Antropologia e História do México (Santa Cruz 335), de que as músicas tocadas possuíam semelhanças com o jarabe e corrido, manifestações semelhantes às boleras e tiranas espanholas, além de possuírem relação com a cultura cigana árabe que havia passado pela Espanha e chegado às Américas pelos portos mexicanos e caribenhos e, talvez, com maior incidência, nos portos cubanos. Com a independência mexicana em 1810 e com a necessidade de criar e reconhecer patrimônios culturais nacionais, o jarabe e son deixam de ser manifestações perseguidas e reprovadas para tornarem-se representantes da alma nacional mexicana, o que fez com que esses bailes fossem institucionalizados e liberados pelas autoridades burocráticas mexicanas. Com isso, passaram a assimilar contribuições de diversas culturas locais. Uma curiosidade a esse respeito relaciona-se a institucionalidades dos bailes. Nessa perspectiva, dizem respeito aos desdobramentos dos perfis dos músicos e das músicas executadas nesses bailes e em um deles relaciona-se aos mariachis. 
desdobrava-se como referência cultural, burocrática, administrativa, o son manifestou-se de maneira abrangente, cotidiana, popular, dinâmica e, de forma irrestrita, pautada nas poesias, assim como nas canções por refrões retratando a vida e humores cotidianos envolvendo a vida dos negros em Cuba.

No livro Motivos de Son (Guillén 54), pode-se destacar como exemplo a poesia Sensemayá (Canción para Matar una Culebra):

¡Mayombe-bombe-mayombé!

¡Mayombe-bombe-mayombé!

¡Mayombe-bombe-mayombé! (Refrão)

La culebra tiene los ojos de vidrio;

la culebra viene y se enreda en un palo; con sus ojos de vidrio, en un palo;

con sus ojos de vidrio.

La culebra camina sin patas;

la culebra se esconde en la yerba;

caminando se esconde en la yerba, caminando sin patas.

(refrão)

Sensemayá, la culebra, sensemayá, Sensemayá, con sus ojos, sensemaya.

Sensemayá, con su lengua, sensemayá.

Sensemayá, con su boca, sensemayá.

¡La culebra muerta no puede comer; la culebra muerta no puede silbar; no puede caminar, no puede correr!

¡La culebra muerta no puede mirar; la culebra muerta no puede beber; no puede respirar, no puede morder!

Sensemayá, se murió! 
O poema descreve um ritual religioso afrodescendente em transfigurações de linguagem em que cosmogonias estimulam a musicalidade estrutural percusiva, mesclando neologismos, temas, termos e referências originárias em relato-testemunho visto e comumente experenciado no cotidiano. O poema para a sua compreensão necessita do entendimento de algumas referencialidades expressas em alguns termos. Sensemayá, por exemplo, é um neologismo que se estrutura como a palavra composta. Sense, em lucumí (yorubá), significa Providência Divina, que, junto com - mayá, supressão da palavra que se refere à deidade Yemanyá, mãe de todos os Orixás, expressa uma mediação, interlocução do que se narra com a mística que representa os afrodescendentes cubanos. A poesia descreve a intervenção de um Deus Supremo (Olóòrun) por meio da matriarca de todas as deidades iorubanas, Yemanyá, no favorecimento da proteção religiosa. Palo Mayombe refere-se a uma das religiosidades afro-cubanas e no poema atua como a mediação de Olóòrun e Yemanyá com os humanos. No poema, a expressão Palo Mayombé, palavra de origem bantú, é reduzida a Mayombé e acrescentada da palavra bombe para estruturar aliteração, sonoridade, ritmo, plasticidade "inscritural" na intenção de efetivar rítmica percussiva que funciona como refrão no poema, espécie de sinestesia ao simular ritual de proteção. Esse recurso representa a autonomia, liberdade simbólica, de corpo e expressão, que incorpora tanto originalidade quanto referencialidade estilística que representa cosmogonia afrodescendente. O poema descreve a caça a uma cobra que representa, simbolicamente, ameaça, traição e, ao mesmo tempo, uma manifestação divina de proteção. O caráter de subversão linguística e temática torna-se, sutilmente, pela linguagem, um instrumento cimarrón na construção poética de Guillén. É, antes, a valorização e busca de uma voz que estruturalmente representasse os ímpetos, valores e recursos expressivos afrodescendentes em Cuba.

Vale ressaltar que a poesia de Nicolás Guillén pode ser interpretada a partir de uma manifestação de interesse humanista de convivência entre culturas de referencialidades distintas em Cuba. Isso significaria repensar as disposições arbitrárias e centralizadoras de uma elite letrada em um projeto de Nação instaurado pela Cidade Letrada. No sentido ajiaco que propôs Ortiz (1942), Guillén apresentou-se como catalizador de uma esperança prática de um equilíbrio isonômico de convivência e reconhecimento. Nesse sentido, tenta redefinir a identidade nacional cubana que se fazia matéria urgente. Afinal, quais os 
Artículo. Rogerio Mendes. "Inscritura e transcuturalidade como poesia e cimarronaje em Nicolás Guillén"

elementos simbólicos que integrariam, comporiam a nação cubana? Ao interpretar a consciência histórica, ancestral e, naturalmente, diversa em Cuba, Nicolás Guillén tenta conciliar conflitos evidenciando valores afro-cubanos na intenção de reconhecê-los distintos, reconhecíveis e válidos dentro de uma sociedade irremediavelmente mestiça como síntese alinhada à realidade latino-americana. Pensar uma nação não apenas como ideia, mas, também, como prática, além da retórica burocrática e social da estirpe de distinção letrada, poderia apresentar-se como entrave para reconhecimentos espontâneos e legítimos, mas que não poderiam deixar de ser validados, inclusive, a partir da perspectiva operada pelos afrodescendentes cubanos em suas vozes e intelectualidades.

O poema Canción del Bongó (Guillén 67) pode ser um exemplo para representar o intento de Guillén como legado propositivo. No poema, o narrador é o próprio bongô. Instrumento marginalizado pela cultura burguesa e letrada predominante na Ilha, mas que se apresenta como dado instrumento conciliador. No poema, Guillén exercita o desejo de harmonia entre as culturas africanas e europeias pela linguagem da música, do son expresso como criação, possibilidade e recurso mestiço de representação identitária cubana:

Esta es la canción del bongó:

Aquí el que más fino sea, responde, si llamo yo.

Unos dicen: Ahora mismo, otros dicen: Allá voy. Pero mi repique bronco, pero mi profunda voz, convoca al negro y al blanco, que bailan el mismo son, cueripardos y almiprietos más de sangre que de sol, pues quien por fuera no es de noche, por dentro ya oscureció. Aquí el que más fino sea, responde, si llamo yo.

En esta tierra, mulata de africano y español (Santa Bárbara de un lado, del otro lado, Changó), siempre falta algún abuelo, cuando no sobra algún Don y hay títulos de Castilla 
con parientes en Bondó:

Vale más callarse, amigos, y no menear la cuestión, porque venimos de lejos, y andamos de dos en dos. Aquí el que más fino sea, responde si llamo yo.

Habrá quién llegue a insultarme, pero no de corazón; habrá quién me escupa en público, cuando a solas me besó...

A ése, le digo:

Compadre, ya me pedirás perdón, ya comerás de mi ajiaco ya me darás la razón, ya me golpearás el cuero, ya bailarás a mi voz, ya pasearemos del brazo, ya estarás donde yo estoy: ya vendrás de abajo arriba, ¡que aquí el más alto soy yo!

O texto apresenta-se como um convite ao baile para celebrar as diferenças. "Pero mi repique bronco, pero mi profunda voz, convoca al negro y al blanco, que bailan el mismo son” (Guillén 45). Não importam as origens, mas a convivência e apaziguamento dos conflitos que se explicariam pelas razões políticas que envolveriam arbitrariedades em prol de vantagens e domínios desumanizadores. Os cueripardos e almipetros são neologismos que representam a indissociabilidiade conceitual e biológica entre brancos e negros. Significaria algo como "brancos de alma preta", "pretos de alma branca", "pretos mestiços", brancos mestiços" a exemplo do que Nicomendes Santa Cruz expressa no poema América Latina (Santa Cruz 319) ao referir-se à essência mestiça dos latinoamericanos "indoblanquinegros", "blanquinegrindios" e "negrindoblancos". O que também se refletiria na maneira como se apresentam os sincretismos religiosos em Cuba: Xangô que representaria Santa Bárbara ou Santa Bárbara que representaria Xangô: "En esta tierra, mulata, de africano y español (Santa Bárbara de un lado, del otro lado, Changó)" (Guillén 45). O poema conclui-se a partir do conceito de ajiaco exposto por Ortiz, através do qual defende a aproximação e igualdade dos povos em Cuba e a 
Artículo. Rogerio Mendes. "Inscritura e transcuturalidade como poesia e cimarronaje em Nicolás Guillén"

mestiçagem como sua representação identitária nacional: "Hay títulos de Castilla con parientes en Bondó” e "ya me pedirás perdón, ya comerás de mi ajiaco, ya me darás la razón...”. Por fim, compreende-se a importância, herança e metáfora do son e da música que representa e se desenvolve como almágama de uma representação estrutural e identitária cubana pelo intento ajiaco cimarrón de Nicolás Guillén.

A tradição religiosa afro-latino-americana fundamentada no mito, trazida pela diáspora africana, bem como suas formas de culto e devoção, ao unir canto, dança e rituais, contribuiu para um processo de desenvolvimento cultural amplo e particular em Cuba e fez com que a afrodescedência ganhasse notabilidade relevante. Os cantos seculares, nomeados patakines, e a percussão dos tambores batá, que acompanham as cerimônias religiosas da Santería, como se estabeleceu nominalmente a religiosidade dos afrodescendentes em Cuba, por exemplo, não se restringiram aos cultos das celebrações religiosas e tornaram-se manifestações populares. A religiosidade para os africanos e afrodescendentes apresenta-se como algo contínuo, razão que explica as relações entre os homens. Por essa razão, a religião foi um oportuno instrumento capaz de integrar culturas e pessoas diversas que acabaram por definir o perfil identitário cubano. A Santería apresentou-se como uma espécie de mescla entre humanismo e cimarronaje na disseminação de tradições, saberes e valores africanos interessados em integrar valores, culturas e pessoas. E, com o passar do tempo e a integração de valores, culturas e pessoas, tornou-se metáfora, síntese histórica do processo de formação cultural e social em Cuba. Processo este fundamentado na fusão de valores e experiências diversas que muitas vezes possibilitou a convivência de motivações e interesses de povos radicalmente distintos na colonialidade.

A Santería, inclusive, possui história semelhante à origem do Candomblé e da Umbanda no Brasil. A Santería é resultado da fusão de religiosidades trazidas pelos homens tornados escravos, vindos da África pela diáspora, com o catolicismo instaurado pelas empresas coloniais nas Américas Espanhola e Portuguesa. O sincretismo religioso cubano, assim como o brasileiro, teve sua origem na fusão de suas divindades com os santos católicos para poder enganar o colonizador espanhol e português e permitir aos negros escravizados conseguir, assim, cultuar a própria religião, sem se submeterem aos castigos por diferirem. Na ocasião em que eram negociados na África, os mercadores de escravos evitavam agrupar africanos de uma mesma origem e idiomas para não facilitar 
motins. Na África, era comum o culto a apenas uma divindade. Na ocasião, para contemplar o culto de todas as divindades, criaram-se cerimônias mais abrangentes em suas reverências e devoção. Assim, em Cuba, Obatalá encontrou seu correspondente na Virgem das Mercedes; Yemanyá sua equivalência na Virgem da Regla; Oxún, em Nossa Senhora da Caridade do Cobre; e Ogún, em Santo Antônio. E ainda: Xangô, em Santa Bárbara, e Babalu Aié, em São Lázaro. No entanto, a noção de sincretismo explica o fenômeno que hibridiza polos religiosos, mas se apresenta insuficiente para dar conta de questões mais sutis a respeito do papel e alcance da religiosidade.

Deve-se ter em mente que, de maneira geral, todas as tradições africanas postulam uma visão religiosa do mundo. O universo visível é concebido e sentido como o sinal, a concretização ou o envoltório de um universo invisível e vivo, constituído de forças em perpétuo movimento. No interior dessa vasta unidade cósmica, tudo se liga, tudo é solidário, e o comportamento do homem em relação a si mesmo e em relação ao mundo que o cerca (mundo mineral, vegetal, animal e a sociedade humana) será objeto de uma regulamentação ritual muito precisa cuja forma pode variar segundo as etnias ou regiões. (Hampate $\mathrm{Ba} 173$ ).

Desse modo, vale salientar, que a religião para os afro-cubanos não seria apenas o culto, a dança e a música, mas, também, religare capaz de unir e transcender a diversidade entre os povos que na Ilha se reuniram. A Santería se consagra por apresentar-se como síntese integrativa de valores, éticas e reflexões ao tomar como base referências africanas, mas, também, por admitir outras referências processadas. Nesse sentido, a função gregária que envolve mitos desdobrou-se e expandiu-se como desenvolvimento de uma concepção particular de humanismo, preocupado com a integração de valores positivos comuns entre partes distintas, e cimarronaje, interessada em manter preservadas matrizes culturais de uma ancestralidade africana e atuação intelectual de seus representantes, tendo como liga a oralidade.

Agora podemos compreender melhor em que contexto mágico-religioso social se situa o respeito pela palavra nas sociedades de tradição oral, especialmente quando se trata de transmitir as palavras herdadas de ancestrais ou de pessoas idosas. O que a África tradicional mais preza é a herança ancestral. $\mathrm{O}$ apego religioso ao patrimônio transmitido exprimese em frases como: "Aprendi com meu Mestre", "Aprendi com meu pai", "Foi o que suguei no seio de minha mãe". (Hampate Ba 174). 
Naturalmente, pelas razões que envolveram a colonialidade e a supremacia cultural dos valores da Empresa Espanhola, a relevância da palavra falada, como Tradição e Ancestralidade, ficou restrita aos afrodescendentes. Pois, no tocante às relações burocráticas e administrativas da Cidade Letrada, as cosmogonias e cosmovisões africanas, ou afro-cubanas, não eram reconhecidas nem estimuladas a manifestarem-se. Ainda que o processo de transculturação cubana favorecesse hibridismos, a arbitrária hierarquização de valores era desfavorável aos afrodescendentes pelas leis, consensos e forças. A pesquisadora María Inés Lagos, no artigo Nancy Morejón, ensayísta: la ciudad letrada desde una perspectiva cubana (2011), publicado na renomada Revista Iberoamericana, dedicada à obra da poeta e ensaísta cubana Nancy Morejón, destaca que a religiosidade cubana foi fundamental para a manutenção de linguagem, cultura e valores africanos em Cuba, responsáveis pelo contraponto e coexistência afrodescendente como manifestações populares no país, o que foi determinante para a identificação de referências e ancestralidades na construção poética e ensaística posteriores numa Cidade Letrada afrodescendente. Por essa razão, entende-se que oralidade é elemento fundamental para conceber e compreender a representação e representatividade dos saberes populares e poética afrodescendente em Cuba.

A pesquisadora e poeta Nancy Morejón no livro Nación y Mestizaje en Nicolás Guillén (2003), lembra que as letras dos cantos rituais conservaram línguas africanas, ainda que muitos termos tenham sido excluídos pelos colonizadores europeus. Isso favoreceu o domínio do castelhano, apesar das inevitáveis influências linguísticas africanas no uso corrente do idioma. Talvez esse dado explique o fato de Cuba, ao contrário do exemplo das Antilhas, colônias francesas e inglesas, não tenha desenvolvido um terceiro idioma, a exemplo do creole. Segundo Nancy Morejón (2003), ao menos até o registro da referência citada, não existe um estudo aprofundando a respeito para saber mais detalhes sobre as razões que justificam os motivos. Ainda que se observe e reconheça o idioma peninsular espanhol como referencial comunicativo, a consciência de um projeto linguístico e poético que reavivasse as contribuições africanas ganhou força por meio de Nicolás Guillén. Isso significa identificar a interferência cimarrona no processo. Nancy Morejón (2003) acredita 
que foi por meio de Nicolás Guillén que Cuba (re)conheceu a força e as possibilidades de sua africanía ao articular linguagem e consciência no que definiria o cubano.

Entre las lecciones que brindaba la poesia del mulato cubano estaba la ahondar y brindar una alternativa a la expresión linguística de la profunda africanía de nuestro ser racional. Sin embargo, el español que se habla y se escribe en Cuba, se afilia a las características generales del español de América. El cuerpo lexical de nuestro idioma, insuflado por vocablos congos y yorubas, ha mantenido la esencia de la lengua hablada en las regiones del sur peninsular. Los acentos locales del habla cotidiana no la enrarecen sino que la dotan de una especificidad que no la oculta sino que la brinda tal como ocurre en México, Venezuela o Argentina. La cadenciosa especificidad del español de Cuba tiene mucho de la síncopa de nuestros ritmos, de antecendente africano, de ese mordaz choteo, de esa capacidad tan ingeniosa para crear metáforas inauditas como por ejemplo llamar una caja de cervezas una jaula de lagartos. (Morejón 190).

A base que fundamentou o pensamento e obra de Nicolás Guillén relacionou-se à recusa de reproduzir o patrimônio intelectual e espiritual espanhol em Cuba. Em meio aos padrões da poesia clássica espanhola institucionalizados na Ilha, a obra de Nicolás Guillén propôs refletir sobre os motivos de reproduzi-los como matriz educacional sobrepondo-se a quaisquer outros referenciais, como os africanos. Uma das intenções do projeto de Nicolás Guillén seria contribuir para o desenvolvimento de um processo de formação literária próxima de uma verossimilhança cubana factível. Isso significaria aproximar os escritores da História do seu povo, do processo de formação da sociedade cubana e dos que contribuíram para a manutenção do espírito idiossincrático cubano, a exemplo dos africanos. Um projeto de formação de uma literatura cubana estaria diretamente relacionado à correspondência de um projeto de formação de uma sociedade atrelado à representação de sua história e valores que teriam como destaque a contribuição afrodescendente. A posição do ensaísta e poeta Guillén define-se a partir do interesse pelo enaltecimento da cultura cubana por meio de seu formalismo crítico e criativo, que se desdobra no reconhecimento da contribuição africana e a sua posição inclusiva marcada como nação, como pode ser observado no prólogo do livro de poesia Songoro Cosongo (Guillén 6):

Diré finalmente que estos son unos versos mulatos. Participan acaso de los mismos elementos que entran en la composición étnica de Cuba, 
donde todos somos un poco níspero. Duele? No lo Creo. En todo caso, precisa decirlo antes de que lo vayamos a olvidar. La inyección africana en esta tierra es tan profunda, y se cruzan y entrecruzan en nuestra bien regada hidrografía social tantas corrientes capilares, que sería trabajo de miniaturista el jeroglífico. [...] opino por tanto que una poesia criolla entre nosotros no lo será de un modo cabal con olvido del negro. El negro - a mi juicio - aporta esencias muy firmes a nuestro coctel. Y las dos razas que en la Isla salen a flor de agua, distantes en lo que se ve, se tienden un garfio submarino, como esos puentes hondos que unen en secreto dos continentes. Por lo pronto, el espíritu de Cuba es mestizo. Y del espíritu hacia la piel nos vendrá el color definitivo. Algún día será: "el color cubano".

\section{A Poesia Son para além do Contrapunteo e Transculturação}

A poesia para Guillén reveste-se, investe-se, como espaço-testemunho de expressão e beleza inaudita ou parcialmente vista. Espaço-testemunho que funda uma poética cimarrona que se relaciona às disposições de outro cubano, Fernando Ortíz, em seu livro Contrapunteo Cubano del Tabaco y el Azúcar (2002), onde estabeleceu relação que parece fundamental para compreender o processo de construção de consciência sócio-histórica cubana por meio do conceito de Transculturação.

Tanto Nicolás Guillén quanto Fernando Ortiz vinculam-se a uma percepção crítica que considerava de pouca visibilidade a contribuição afrodescendente no processo de formação social e literária hispano-americana e, mais especificamente, em Cuba, onde o dado afrodescendente reconhece-se fundamental para compor o mosaico multiconstitutivo das culturas na América Latina. Uma das instrumentalidades referenciais relaciona-se ao conceito de transculturação proposto pelo sociólogo Fernando Ortiz. Este, em sua aludida obra, reconhece que a Transculturação é relevante por

[...] expresar los variadíssimos fenómenos que se originan en Cuba por las comprejísimas transmutaciones de culturas que aquí se verifican, sin reconocer las cuales es imposible entender la evolución del pueblo cubano, así en lo económico como en lo institucional, jurídico, ético, religioso, artístico, linguístico, psicológico, sexual y en los demás aspectos de su vida. La verdadera historia de Cuba es la historia de sus intricadísimas transculturaciones. (Oriz, 2002, 254). 
Os esforços de Ortiz, por meio da ideia da Transculturação, serão marcados pela tentativa de integrar os negros cubanos à conformação de uma identidade nacional que, naturalmente, relaciona-se ao processo de desenvolvimento histórico cubano que, segundo suas percepções, reconhecia, além das contribuições culturais afrodescendentes, as influências de culturas outras, estrangeiras. Reconhece-se, desse modo, que o entendimento do conceito de Transculturação, dado fundamental de coesão para conceber idealmente uma sociedade, levaria à disposição de reduzir a discriminação social dos negros. Uma perspectiva que naturalmente se contrapõe às evidentes conveniências dos interesses de uma oligarquia colonial instaurada, ainda que se perceba nos desdobramentos atenuantes de conflitos étnicos inevitáveis e intermitentes pelos projetos e jogos de interesse na manutenção do poder econômico. Compreende-se, por essa razão, que a prioridade de Ortiz, assim como de Nicolás Guillén, seria o fortalecimento de uma integração nacional cubana aos moldes do que se poderia compreender e conceber Cuba como uma nação moderna, republicana e democrática a partir da problematização do mito da coexistência pacífica das realidades culturais que coabitavam entre si - indígena, africana e europeia em função de uma referencialidade organizacional que não considerava a contento as contribuições de sua maioria negra, embora se reconhecesse a contribuição africana fundamental para se construir um sentimento de cubanía abrangente. Esse dado fundamental estaria justamente no contapunteo de tabaco y azúcar, que seria a metáfora de compreensão do equilíbrio histórico das forças culturais endógenas e exógenas que comporiam o caráter da compreensão social cubana. $\mathrm{O}$ que poderia ser relacionado a uma proposição de sociabilidade amistosa, cordial das relações, no intuito, talvez, de superar os irremediáveis conflitos entre as configurações internas e que, ao mesmo tempo, possibilitaram as relações transculturais que se estabeleciam como mecanismo de síntese e constantes dinâmicas sociais, evolutivas. É interessante pensar a maneira como foi concebida a compreensão do contrapunteo. Contrapunteo, feliz e concisa ideia que em sentido terminológico também pode ser relacionada a uma tradição oral que se vincula a uma ideia original de "desafio", "peleja", "disputa", como pode ser observado em manifestações de disputa em trovas, rap, e que também sugere subjetividades insurgentes dos cimarrones que de alguma maneira incorporam-se ao sentido da leitura crítica de Ortiz. A compreensão do tabaco como elemento simbólico, metáfora de preservação cultural da 
Artículo. Rogerio Mendes. "Inscritura e transcuturalidade como poesia e cimarronaje em Nicolás Guillén"

ancestralidade indo-caribenha, e, ao mesmo tempo, como produto que viabilizava e legitimava a economia e o desenvolvimento nacional cubanos é uma das demonstrações eficazes da compreensão de Ortiz sobre como atuaria a transculturação: como uma rede, uma trama, um tecido, um cruzo de legitimação cimarrona na medida que se preservam dados contributivos importantes da cosmogonia originária no processo de formação e compreensão da sociedade cubana

La religión es entre los primitivos "el cemento de su vida social", como ha dicho Malinowski, y el tabaco ligaba toda la vida individual del indio a la de su sociedad. [...] En el Pueblo indio el tabaco formaba parte integrante de su mitologia, de su religión, de su magia, de su medicina, de sus cerimonias tribales, de su política, de sus guerras, de su agricultura, de su pesca, de sus estímulos, colectivos, de sus costumbres públicas y privadas. El uso de tabaco o el manejo de su potencia no era superstición ni herejía, sino una instituición religiosa, ortodoxa e inveterada. Los ritos del tabaco eran actos sociales y forzosos, en cuya realización, singular o colectiva, estaba interessado todo el grupo humano, el cual exigia, su practica en las formas precisas y sacras fijadas por la tradición. Por ser una instituición social, entre los indios el tabaco se enlazaba también con la vida económica. Como el canto o el baile, el tabaco entre ellos era parte de los ritos sacrosociales que intervenian en la realización de las más importantes atividades económicas, como la comida, la caza, la agricultura, el tejido de una red o el habrado de una canoa; pero el tabaco por sí no era un fenómeno substancialmente económico. (Ortiz, 2002, 417).

No que diz respeito à compreensão simbólica e contributiva do açúcar, Ortiz atribui relação de desenvolvimento capitalista, extrativista e exploração da escravidão africana no desenvolvimento latifundiário da formação nacional cubana. Nas palavras do pesquisador João Francisco de Oliveira Simões, em sua tese de doutoramento Os projetos Intelectuais de Fernando Ortiz e de Gilberto Freire (2017), as diferenças entre o tabaco e o açúcar consistiam-se como complementares na perspectiva de seu contrapunteo para pensar a articulação e interpretação da realidade cubana. Ortiz concebeu

[...] o tabaco como centro irradiador de aspectos positivos para a formação da nação e do povo cubano. Por outro lado, reserva ao complexo do açúcar o papel de difusor de traços negativos à formação nacional. $\mathrm{O}$ tabaco, produto nativo, significava a possibilidade de coesão social, vinculação com a terra, sociabilidade, autonomia e liberdade. 
Enquanto o açúcar, produto estrangeiro, era símbolo do absenteísmo, da escravidão, do latifúndio, do capitalismo; uma força opressora e dissociadora. (Simões 149).

Os engenhos funcionavam como células, organismos sociais vinculados à extração e comércio externo. Os bens da produção eram privados e as atividades econômicas eram vinculadas ao poder centralizador e autoritário das oligarquias. Não havia um compromisso de reconhecimento e valorização, em sua estrutura de interesses, com a dimensão humana da Ilha. Essa estrutura incentivava o tráfico negreiro e a subalternização dos afrodescendentes, que eram submetidos a valores e normas que propiciavam estratificação e desenvolvimento cultural econômico alheios aos valores e reconhecimentos dos patrimônios humanos da mão de obra escrava. Tratou-se de uma Máquina Produtiva estrangeira que desenvolvia produção, benefícios e culturas dos estrangeiros em um processo que desconsiderava contribuições humanas como contrapartidas. A produção açucareira desconfigurava a ideia de um projeto comprometido com uma ideia de nação soberana e equilibrada entre suas partes integrativas.

En el azúcar el predomínio extranjero siempre fue notable y en el presente es casi exclusivo. El tabaco ha sido siempre más cubano que el azúcar por su nacimiento, por su espíritu y por su economía. La razón es obvia. El azúcar siempre ha exigido mucho capital; hoy en día una enorme fortuna. [...] Además, desde que los ingenios se instalan en América, todos sus elementos, salvo la tierra, hay que traerlos de países ultraoceánicos. Las máquinas, los trabajadores los dineros que inverten, todo hay que importarlo y esto implica aún mayor necesidad de gran capital. Si la indústria azucarera es capitalista desde inicio, a la medida que mejora la tecnica mecânica, al llegar la maquina de vapor, se requeiren más costosos trapiches, más cañaverles, más tierras, más esclavos, más inversiones y reservas; en resumen, más y más capital. Toda la historia del azúcar en Cuba, desde su primer día, es la lucha por la traída del capital foráneo y su injerencia primordial en la economia insular. Y precisamente, no del capital español sino del más extranjero: del genovês, del alemán, del flamenco, del inglés y del yanqui, desde los días del emperador Carlos V con sus banqueros en los Fúcares hasta estos modernos días del "buen vecino" y los financeiros de Wall Street. (Ortíz 210-11). 
Artículo. Rogerio Mendes. "Inscritura e transcuturalidade como poesia e cimarronaje em Nicolás Guillén"

Nota-se que, tanto na perspectiva do tabaco quanto do açúcar, o elemento da afrodescendência apresenta-se modelar, protagonista e socialmente desfavorável na manutenção da operacionalidade econômica cubana que subalternizava os negros. Não seria absurdo considerar que o desenvolvimento de uma consciência e ação que favorecessem o afrodescendente cubano consistisse na mobilização de uma poética guilleniana que buscasse valorizar subjetividades e patrimônios culturais afrodescendentes não visibilizados no processo. Ao levar em consideração que a obra de Ortiz possui vários momentos sobre a relação entre a afrodescendência e a cultura cubana, atém-se, aqui, ao momento em que situa socialmente o negro na construção sócio-histórica que fundamenta o conceito de Transculturação. Conceito este que, em sua dialética, aproxima-se do que também Nicolás Guillén desenvolveu em sua poética. Por essa razão, tão importante quanto o conceito de Transculturação fundamentado por Ortiz para Nicolás Guillén é o que, segundo o historiador e pesquisador Fernando Vale Castro, em seu artigo Raça no Pensamento do Intelectual Cubano Fernando Ortiz (29), Fernando Ortiz posteriormente considerou: o conceito ajiaco, no artigo A Cubanidade e os Negros (1939), publicado no Suplemento Panamericano do Jornal A Manhã, metáfora para compreender que o elemento central da identidade nacional cubana deveria negar hierarquias raciais. "Os abraços amorosos da mestiçagem como augurais de uma paz universal dos sangues [...] de uma possível, desejável e futura desracialização da humanidade” (Ortiz , 1939, 9 cit. Castro, $2015,29)$.

A cubanidade não pode depender simplesmente da terra cubana, onde se nasceu e nem da cidadania política que se goze: e às vezes se sofre. $\mathrm{Na}$ cubanidade "há" algo mais do que um metro de terra molhada, do que o primeiro choro de um recém-nascido, algo mais que algumas polegadas de papel branco, marcados com selos e gravuras simbólicas de uma autoridade que reconhece uma vinculação social verdadeira ou suposta. A cubanidade não dá origem: não há uma raça cubana e não há raça pura, não há nenhuma. A raça, afinal, não é mais do que um estado civil firmado por autoridades antropológicas; mas esse estado racial sabe ser tão convencional e arbitrário, e às vezes tão mutável, como o estado civil delimita o homem a tal ou qual nacionalidade. A cubanidade para o indivíduo não está no sangue, nem no papel, nem na habitação. A cubanidade é, sobretudo, a qualidade peculiar de uma cultura, a de Cuba. Dito em termos correntes, a cubanidade é a condição da alma, complexo de sentimentos, ideias e atitudes? [...] Mas, se todas essas culturas 
recebessem eflúvios da cubanidade, em qual delas se destilou mais a cubania? Como ocorre como ajiaco, o sintético e o novo estão no fundo das substâncias decompostas, precipitadas, revoltas, fundidas e assimiladas em um jogo comum; combinam numa mistura de gentes, culturas e raças. (Ortiz, 1942, 9).

A "rebeldia" cimarrona de Nicolás Guillén incide ao questionar, como consequência de uma realidade socioeconômica adversa aos negros, a influência e predominância de uma tradição literária europeia que invisibilizava o caráter essencial de uma cultura cubana que ousou expor a partir da liberdade de dizê-lo como poesia. Ousou dizê-lo a partir das maneiras e lugares onde transitavam os valores, temas e formas da liberdade e expressão referencial que estariam nas ruas, nas músicas e maneira particular de falar, com a beleza e a força da sonoridade que passou a ser lida como expressão crítica do que intuía e naturalmente representava como poesia. Algo que pode ser percebido nos poemas Hay que "Tené boluntá” (“[...] bucate un real/cómprate un paquete' vela/porque a la noche no hay lu”, p. 13); "Bucate Plata” (“[...] bucate plata/ poqque no doy un passo má/ etoy arró com galleta [...]”, p. 25) ou em Tu no sabe inglé (“[...] La mericana te buca/y tú le tiene que huí/ tu inglé de etrái guan/ de etrái guan y guan tu tri [...]”, p. 31) (Guillén, 1957), onde se encontra uma expressividade que ignora a suposta falta de letramento popular pela supressão de plurais, desinências para afirmar a expressão da transcrição da fala popular e o sentimento de uma condição social adversa afrodescendente, pois afirmar uma norma culta não seria, necessariamente, tê-la como exemplo ou modelo diante de outra realidade que se afirmava. Nicolás Guillén, por essa razão, baseado na ilustração cimarrona que representa e define sua cultura, pensou e escreveu a si e a Cuba em expressão real e cotidiana com o que representa e que foi interpretado como vanguarda na compreensão em alguns dos manuais de Crítica e Historiografia Literária, a exemplo do que foi exposto por Jorge Schwartz, no livro Vanguardas Latino-Americanas: Polêmicas, Manifestos e Textos Críticos (2008).

O acadêmico afro-costa-riquenho Quince Duncan compreende a poesia do cubano Nicolás Guillén como "afrorrealista”, ainda que o próprio Guillén não o tenha assim concebido. No artigo El Afrorrealismo: Una Nueva Dimensión de la Literatura Latinoamericana (2006), com base na obra de Nicolás Guillén, vislumbra as bases do que poderia ser compreendido como uma Literatura Afro-Hispano-Americana. O Manifesto foi pensado e publicado como resposta à provocação se seria possível uma literatura "afro" no 
contexto hispânico, pois, durante muito tempo, questionou-se a possibilidade, em razão das demandas artísticas e fortunas críticas que até meados dos anos 70, no contexto hispanoamericano, interessaram-se tão somente pelos padrões da poesia clássica espanhola. A partir da publicação de autores como Nicolás Guillén, que não se utilizava de referentes tradicionais castelhanos, os críticos passaram a entender a importância das particularidades e necessidades expressivas independentes e originárias. Tratava-se de uma poética que não evocava mitos greco-latinos nem folclorismos; não era literatura negrista, nem reproduzia os valores do pensamento da Negritude. Para Duncan (2), era uma nova expressão que realizava uma subversão africanizante do idioma, “[...] recurriendo a referentes míticos inéditos o hasta ahora marginales, tales como el Muntu, el Samanfo, el Ebeyiye y referencias a deidades como Yemanyá y a la incorporación de elementos del criollo costeño", e que se expressava de maneira honesta, por também incluir os elementos da referencialidade do negro no estatuto da legitimidade da Literatura e Cultura LatinoAmericanas, em perspectiva corrente e cotidiana, uma condição real de existência que poderia ser articulada como escrita e poética. Tais elementos não eram meramente acessórios, mas, sim, medulares na forma de reconciliar-se com uma herança cultural arrebatada, ao mesmo tempo que a transformavam em labor de expressividade estética. Pensou que essa seria uma oportunidade para trazer à tona contribuições não arroladas pelos fundamentos historiográficos e críticos da Literatura Hispano-Americana. Desse modo, compreendeu, com base em Guillén e outros autores afrodescendentes, bases críticas a serem consideradas: 1) a reivindicação da memória simbólica africana; 2) a reestruturação informada da memória histórica da diáspora africana; 3) a reafirmação do conceito de comunidade ancestral; 4) a adoção de uma perspectiva crítica intracêntrica; e 5) a busca e proclamação da identidade afro na Cultura Latino-Americana. Com isso haveria critérios suficientes, segundo Duncan (2006), para revisar valores e epistemologias disseminadas desde os tempos coloniais pelos europeus - por meio do eurocentrismo, da eurofilia e da etnofobia - que interferiam de maneira negativa no processo de formação social e cultural hispano-americana por meio do processo de formação literária que corresponderia também ao processo de desenvolvimento das sociedades latino-americanas. 


\section{REFERÊNCIAS}

Duncan, Quince. "El Afrorrealismo. Una Nueva Dimensión de la Literatura Latinoamericana". La Jiribilla, 1 de abril de 2006, http://www.lajiribilla.cu/2006/n272_07/272_06.html Consultado el 6 de octubre de 2014.

Guillén, Nicolás. Sóngoro Cosongo; Motivos de Son; West Indies Ltd; España, Poema en Cuatro Angustias y Una Esperanza. Editora Losada, 1957.

Hampate Ba, Amadou. "A Tradição Vida". História Geral da Africa I. Metodologia e PréHistória da África, edición de Joseph Ki-Zerbo. Unesco, 2010, pp. 167-212.

Lagos, María Inés. "Nancy Morejón, ensayísta: la ciudad letrada desde una perspectiva cubana". Revista Iberoamericana, vol. 77, núm. 235, 2011, pp. 539-556.

Mendes, Rogerio. Pedagogias da Cimarronaje. As Contribuições das Cosmogonias e Cosmovisões Africanas e Afrodescendentes para a Critica e Historiografia Literaria (Afro-)Latino Americana. 2019. Programa de Pós-Graduação em Letras, Universidade Federal de Pernambuco, Tese (Doutorado em Teoria da Literatura).

Morejón, Nancy. Nación y Mestizaje en Nicolás Guillén. Ediciones Unión, 2003.

Ortiz, Fernando. "A Cubanidade e os Negros". Suplemento Panamericano do Jornal A Manhã, 30 de agosto de 1942, p. 7.

Ortiz, Fernando. Contrapunteo Cubano del Tabaco y el Azúcar. Cátedra, 2002.

Queiroz, Amarino Oliveira de. As Inscrituras do Verbo: Dizibilidades Performáticas da Palavra Poética Africana. 2007. Programa de Pós-Graduação em Letras, Universidade Federal de Pernambuco, Tese (Doutorado em Teoria da Literatura).

Santa Cruz, Nicomedes. Obras Completas II: Investigación (1958-1991). Livros en Red, 2004.

Schwartz, Jorge. Vanguardas Latino-Americanas: Polêmicas, Manifestos e Textos Críticos. EdUSP, 2008.

Simas, Luiz Antonio y Luiz Rufino. Fogo No Mato. A Ciência Encantadas das Macumbas. Mórula, 2018a.

---. "Sobre Olhar um Terreiro para Enxergar um País". Suplemento Pernambuco, 23 de abril de 2018, p. 9.

---. Por una "Epistemología Macumbera y una reivindicación de los saberes subalternizados". Revista Diversa, Red de Estudios de la Diversidad Religiosa en Argentina, 29 de marzo de 2019. http://www.diversidadreligiosa.com.ar/blog/poruna-epistemologia-macumbera-y-una-reivindicacion-de-los-saberessubalternizados/?fbclid=IwAR30f0E_YTlQaZqJBdMNTtuV7ZTj4rgwwjo6xs0Hnli _Q45YfAgo8E-xY1U. Consultado el 5 mayo de 2019.

Simões, João Francisco de Oliveira. Os Projetos Intelectuais de Fernando Ortiz e de Gilberto Freire. 2017. Instituto de Filosofia e Ciências Humanas Universidade Estadual de Campinas, Tese (Doutorado). 